\title{
ESTADO E BURGUESIA NO \\ CAPITALISMO NEOLIBERAL
}

\author{
Armando Boito Jr.
}

\section{RESUMO}

O artigo é fruto de pesquisa ainda em curso e procura fazer um tipo de análise que foi, em grande medida, deixado de lado no Brasil. Reatando com uma rica tradição da Sociologia e da Ciência Política brasileiras, que se formou nos anos 1960 e 1970, o autor tenta examinar os interesses das frações da burguesia brasileira que chegam a agir como frações distintas no processo político nacional, bem como as relações desses interesses com a política de Estado. São examinados também os conflitos entre essas frações burguesas e as relações que, enquanto frações burguesas de um país dependente, elas entretêm com o imperialismo e com o campo das classes populares. Sempre em uma abordagem tentativa e inicial, o artigo faz referência também à mudança na hierarquia do poder burguês, isto é, à mudança ocorrida no interior do bloco no poder, durante os mandatos presidenciais de Luiz Inácio Lula da Silva. O artigo apresenta a hipótese segundo a qual a nova vaga de internacionalização do capitalismo dependente brasileiro não impediu que um poderoso setor da grande burguesia interna continuasse atuante e melhorasse sua posição no bloco no poder ao longo da década de 2000.

PALAVRAS-CHAVE: Estado brasileiro; burguesia; bloco no poder; hegemonia; teoria marxista.

\section{INTRODUÇÃO}

Antes de entrar no tema propriamente dito, peço ao leitor que me acompanhe em uma pequena digressão que servirá para situar teoricamente o meu trabalho.

Existe uma rica tradição de estudos sobre as classes proprietárias no Brasil. Tais estudos são heterogêneos no que respeita às suas orientações teóricas e preocupações e passaram, nos anos recentes, por modificações importantes.

O tema mais tradicional desses estudos é a grande agricultura de exportação. $\mathrm{O}$ estudo desse tema remonta, para restringirmo-nos a autores do século XX, aos trabalhos de Octavio Brandão, Caio Prado Jr., Nelson Werneck Sodré, Pierre Monbeing, Celso Furtado, Florestan Fernandes e outros precursores das Ciências Sociais, da Economia Política e do debate intelectual moderno sobre o Brasil. A economia e a sociedade da canade-açúcar, na região Nordeste, e do café, na região Sudeste, são os temas nobres dessa tradição bibliográfica. Os estudos sobre os empresários industriais são mais recentes, mas estão longe de serem novidade. Nelson Werneck Sodré, Florestan Fernandes, Octavio Ianni, Hélio Jaguaribe, Fernando Henrique Cardoso, Warren Dean, Boris
Fausto, Luciano Martins e muitos outros passaram a dedicar-se, conforme implantava-se e aprofundava-se o processo de industrialização no Brasil do período posterior a 1930, aos estudos sobre a burguesia industrial. Alguns desses autores foram os primeiros a analisar os industriais utilizando o conceito de "burguesia". Fizeram-no para pensar as relações políticas complexas desse setor social com os centros hegemônicos do capitalismo, com o Estado e com os trabalhadores. Esses estudos, embora alguns deles carecessem de levantamento empírico mais sistemático, são muito sofisticados, ensejaram debates vivos e produtivos e estiveram ligados, de maneira aberta ou implícita, à discussão política sobre os rumos da economia e da sociedade brasileiras. Como é sabido, o debate sobre a burguesia industrial concentrou-se na questão de averiguar se existia, no Brasil, uma burguesia nacional com interesse em participar de uma ampla frente de classes por um desenvolvimento nacional autônomo.

As orientações teóricas desses estudos eram variadas. Pensemos, por exemplo, na diferença entre, de um lado, o marxismo de tipo soviético praticado por Nelson Werneck Sodré, para o qual a burguesia era o sujeito social dirigente de um processo de desenvolvimento "de tipo capitalis- 
ta”, e, de outro lado, a Economia Política de Celso Furtado, que fundia a teoria econômica de Keynes com a Sociologia de Karl Mannheim, imputando à intelligentsia a função de conduzir o desenvolvimento, concebido, no caso de Furtado, como "desenvolvimento econômico" simplesmente (MONTEIRO, 2006). Apesar dessa variedade de orientações teóricas, boa parte desses estudos foi realizada por autores marxistas ou influenciados, em maior ou menor grau, pela teoria marxista. Esses trabalhos operavam, como foi indicado nas referências acima, com o conceito de "classe social" e, no que respeita à burguesia, esse conceito era pensado de modo complexo, comportando uma subdivisão dessa classe em frações (nacional, associada, agrária, industrial etc.), cujos interesses específicos produziriam efeitos pertinentes no processo político nacional. Os conceitos de "burguesia", "Estado capitalista", "imperialismo", "desenvolvimento capitalista” e outros estiveram na base do estudo do Estado formado no posteriormente a 1930, da ideologia nacional-desenvolvimentista, da política de industrialização e de eventos marcantes da história política do Brasil, como a própria Revolução de 1930 e o golpe militar de 1964. Pois bem: esse tipo de análise perdeu terreno nas Ciências Sociais e quase caiu em desuso no ambiente universitário ${ }^{1}$.

O declínio desse tipo de pesquisa é um dos episódios que fazem parte do declínio do prestígio do marxismo na universidade brasileira - algo que não é, diga-se de passagem, homogêneo no mundo universitário, pois nessa mesma época o marxismo iniciava sua trajetória ascendente na universidade estadunidense. Noções como "classe social”, "fração de classe”, "ideologia” e "Estado de classe" desapareceram, no Brasil, da pesquisa sobre empresários industriais, banqueiros e agronegócio. Na maioria dos casos, estudam-se tais setores como grupos que competem entre si, como fazem quaisquer outros grupos, para influir na política de Estado - entidade que é apresentada, implicitamente, como uma arena neutra para a disputa entre interesses múltiplos e situados em condições de igualdade uns frente aos outros. Outra característica de estudos mais recentes consiste em isolar o setor da burguesia que se pretende estudar dos demais setores ou frações e,

\footnotetext{
${ }^{1}$ Esse tipo de pesquisa não desapareceu completamente no período recente. Recordo, a esse título, o trabalho de Renato M. Perissinotto (1994).
}

mais ainda, do restante da sociedade. Hoje, discutir a possibilidade de aliança desta ou daquela fração burguesa com outras classes ou setores sociais poderá parecer a muitos como uma questão fora de propósito. É certo que os estudos recentes ganharam na fundamentação empírica e no levantamento sistemático das informações; avançaram, também, na análise da relação dos empresários com o processo decisório no Estado. Por isso, trazem contribuição importante para o conhecimento do Estado e dos capitalistas brasileiros. Nesse sentido, são exemplos os trabalhos de Ary Minella, para o caso dos banqueiros; de Eli Diniz e Renato Boshi, para o caso dos empresários industriais, e de Adriano Nervo Codato, para citar apenas alguns dos mais conhecidos e que são, pela sua qualidade, referências incontornáveis no estudo da burguesia brasileira ${ }^{2}$.

O nosso trabalho de pesquisa sobre a burguesia brasileira procura retomar a tradição marxista que hoje está quase esquecida nessa área de estudo, sem a pretensão de equiparar - convém dizêlo - a qualidade do nosso trabalho à daqueles que citamos mais atrás. Concebemos o conjunto do empresariado - banqueiros, industriais, fazendeiros, comerciantes - como integrantes da classe capitalista e o Estado brasileiro como uma entidade moldada, pelas suas instituições e pelo pessoal que as ocupa, para servir aos interesses fundamentais dessa classe social. Ademais, no campo da teoria marxista das classes e do Estado, trabalhamos com o conceito específico de "bloco no poder”, desenvolvido por Nicos Poulantzas para pensar a classe burguesa como a unidade (classe social) do diverso (frações de classe) nas suas relações com o Estado e com o restante da sociedade (cf. POULANTZAS, 1971, v. II, parte III, cap. 4; parte IV, cap. 4).

O emprego do conceito de bloco no poder exige, em primeiro lugar, que o pesquisador detecte as frações da classe dominante que agem como força social distinta em uma dada conjuntura, isto é, os interesses econômicos setoriais burgueses que ensejam, diante da política de Estado, a formação de grupos diferenciados que

\footnotetext{
2 Refiro-me aos inúmeros trabalhos de Eli Diniz e Renato Boschi sobre o empresariado industrial e aos diversos trabalhos de Ary Minella sobre os empresários do setor bancário. Penso também em trabalhos como os de Adriano Nervo Codato (1997) e de Paulo Neves Costa (1998).
} 
perseguem, no processo político, objetivos próprios. Em segundo lugar, exige que o pesquisador procure esclarecer quais interesses de fração são priorizados pela política econômica do Estado e quais são relegados a um plano secundário. A localização dos interesses efetivamente priorizados pela política do Estado indica qual é a fração hegemônica no interior do bloco no poder. Poulantzas sugere que, regra geral, o bloco no poder no Estado capitalista apresenta uma hierarquia mais ou menos estável, configurando a existência de uma fração hegemônica no seu interior. Contudo, esse autor também contempla a possibilidade de uma crise de hegemonia, que é a situação de um bloco no poder em que nenhuma fração burguesa logra impor seus interesses específicos como interesses prioritários para a política de Estado. O conceito de bloco no poder, que recobre o terreno das classes e das frações de classe, permite também a Poulantzas realizar um enfoque novo e sofisticado dos regimes políticos nos Estados democráticos, remetendo as formas de governo (presidencialismo ou parlamentarismo), as disputas entre os ramos do aparelho de Estado (poderes Executivo e Legislativo), o jogo partidário (os variados tipos de pluripartidarismo e bipartidarismo) às disputas por hegemonia no interior do bloco no poder (idem, v. II, parte IV, cap. 5). A idéia é que a organização do Estado e o sistema partidário encontram explicação nos interesses burgueses em conflito.

Há um forte preconceito contra a corrente marxista althusseriana nos meios marxistas brasileiros. Porém, recorrendo a Poutantzas, não nos colocamos distantes, ao contrário do que poderia parecer à primeira vista, da tradição brasileira à qual fizemos referência. Os estudiosos brasileiros operavam com noções e teses que aproximavam suas análises daquelas que poderíamos obter utilizando, explícita e conscientemente, o conceito poulantziano de bloco no poder e o tratamento que esse conceito sugere para o regime político. A polêmica de Boris Fausto com Nelson Werneck Sodré sobre a Revolução de 1930 não dizia respeito ao conflito entre diferentes frações no interior da classe capitalista? Sodré, em uma breve passagem realçada, talvez exageradamente, por Fausto, apresentou a Revolução de 1930 como um golpe da burguesia ascendente contra a classe decadente dos proprietários de terra, enquanto Fausto, para refutá-lo, tratou de apresentar 1930 como fruto de uma crise oligárquica, entendida esta como uma crise provocada pelas disputas entre as frações regionais da classe dominante. Há um amplo terreno comum a esses dois trabalhos - terreno comum que era, aliás, o que permitia o tipo de discussão que eles ensejaram. O processo político expressa, em ambos, a ação e os interesses de classe; em ambos, o Estado é, antes e depois de 1930, o Estado da classe dominante. Qual, então, a diferença? No trabalho de Sodré, muda a classe ou a fração da classe dominante cujos interesses predominam no Estado - decadência dos grandes proprietários de terra, ascensão política da burguesia -; no trabalho de Fausto, os conflitos entre os setores regionais da classe dominante, as chamadas dissidências oligárquicas, teriam aberto um período de crise de hegemonia, noção expressamente utilizada por esse autor e que já fora utilizada antes por Francisco Weffort nos seus estudos sobre o populismo nascido posteriormente a 1930. Quando Antônio Carlos Meirelles, em excelente e pouco conhecido texto, interveio no debate para fazer a crítica da crítica de Fausto, foi a vinculação entre o regime político e o bloco no poder que serviu de referência (MEIRELLES, 1973). Meirelles argumentou que, embora Fausto tivesse demonstrado a ausência da burguesia industrial no movimento que depôs Washington Luís e a importância da crise oligárquica para o desencadeamento do movimento político-militar, permanecia o fato de que a centralização do regime político alterara a relação de forças no interior do bloco no poder, abrindo caminho para a política de industrialização que se tornaria clara no final da década de 1930. Por isso, Meirelles utilizou a noção gramsciana de revolução (burguesa) passiva para caracterizar o movimento de 1930.

Algo semelhante passa-se com as discussões sobre a burguesia nacional. Como é sabido de todos, Fernando Henrique Cardoso, nos seus estudos sobre o empresariado e sobre a dependência, esforçou-se para refutar a tese, que ele atribuía genericamente aos intelectuais comunistas e ao Partido Comunista Brasileiro (PCB), segundo a qual haveria uma burguesia nacional passível de assumir, no Brasil, uma postura anti-imperialista (CARDOSO, 1966). Nos debates sobre o significado dos golpes de Estado de 1954 e 1964, a questão da existência ou não de um projeto de desenvolvimento capitalista autônomo e de uma burguesia nacional foram questões que marcaram a Ciência Política brasileira (IANNI, 1972). 
O declínio do prestígio da teoria marxista na universidade brasileira, o abandono das pesquisas sobre a burguesia como classe social e a última onda de internacionalização da economia capitalista - o denominado processo de mundialização poderiam sugerir que esse enfoque e os debates que ele enseja estariam superados. Nós acreditamos que não. Além de trabalharmos com o conceito de bloco no poder, lançamos mão de um outro conceito específico, também produzido por Nicos Poulantzas - o conceito de "burguesia interna” - para entender boa parte do que ocorre hoje com a burguesia brasileira nas suas relações com o Estado e com o capitalismo internacional ${ }^{3}$. Entendemos que o denominado processo de mundialização não logrou absorver, integralmente, a burguesia de um país dependente da semiperiferia, como o Brasil, o que significa que os conflitos entre uma burguesia compradora, que é o braço local da atual forma de dependência, e uma burguesia interna, com base de acumulação e nos interesses específicos, explicam parte importante do processo político nacional. Com tais conceitos, elaboramos duas hipóteses principais de trabalho. A primeira é que vigoraria, no período neoliberal, iniciado no governo Collor e que se estende até o presente, a hegemonia do grande capital financeiro internacional, junto ao qual os grandes bancos brasileiros funcionam como burguesia compradora. A segunda hipótese é que o governo Lula representa uma novidade: sem romper, até aqui, com a hegemonia do grande capital financeiro internacional, Lula promoveu a ascensão política da grande burguesia interna brasileira no interior do bloco no poder. Isto é, o governo Lula, pelo menos no tema que nos ocupa, que é o tema do empresariado e de sua relação com o Estado, não seria, a despeito de manter o modelo neoliberal, uma mera continuidade do governo Fernando Henrique Cardoso (FHC).

\section{O BLOCO NO PODER NO PERÍODO NEO- LIBERAL}

A política econômica e social do Estado brasileiro ao longo das duas últimas décadas conferiu

\footnotetext{
3 O conceito de burguesia interna indica a fração da burguesia que ocupa uma "posição intermediária" entre a burguesia compradora, que é uma mera extensão dos interesses imperialistas no interior dos países coloniais e dependentes, e a burguesia nacional, que em alguns movimentos de libertação nacional do século XX chegou a assumir posições anti-imperialistas. Ver Poulantzas (1976).
}

ao capitalismo brasileiro certas características minimamente estáveis que permitem que falemos em um novo modelo de desenvolvimento capitalista. Esse modelo, que tem sido chamado neoliberal, pode ser definido por meio de um contraste com o modelo que o antecedeu, o desenvolvimentista - tanto na sua fase nacional reformista (1930-1964) quanto na prómonopolista da ditadura militar (1964-1985). Muitos elementos evidenciam esse contraste entre modelo desenvolvimentista e modelo neoliberal: o ritmo do crescimento econômico cai, o papel do Estado como empresário e provedor de serviços declina, a prioridade ao crescimento e ao desenvolvimento industrial desaparece, a desnacionalização da economia nacional ampliase e os direitos sociais e trabalhistas sofrem um processo de redução ainda maior do que aquele que sofreram durante a fase ditatorial-militar do modelo desenvolvimentista. Esses elementos fornecem-nos as pistas para detectarmos qual é a fração burguesa hegemônica ao longo do período neoliberal. Para tanto, deveremos detectar qual fração burguesa é prioritariamente beneficiada pelas características do novo modelo.

No período do modelo capitalista desenvolvimentista, verificou-se uma expansão, ainda que limitada e não-linear, dos direitos trabalhistas e sociais. O modelo neoliberal de capitalismo inverteu essa tendência. Desse elemento sobejamente conhecido, podem-se tirar conclusões novas. Na medida em que tal elemento contempla os interesses do toda a burguesia brasileira e do capital internacional aqui investido, ele deve ser considerado um elemento que tem assegurado uma unidade política mínima da burguesia em torno do modelo neoliberal ${ }^{4}$. Muitos analistas, dentre os quais se destacam os economistas críticos da Comissão Econômica para a América Latina e o Caribe (Cepal), não percebem esse fato. Constatando que o modelo neoliberal promove a desindustrialização do país - entendida como a redução do produto industrial no conjunto do produto interno bruto e como o rebaixamento tecnológico da indústria instalada -, demonstram sua perplexidade diante do apoio ou das críticas

\footnotetext{
4 Nesta parte do texto, retomo, com nova formulação, parte do que já escrevi em trabalho anterior sobre o bloco no poder no conjunto do período neoliberal. Ver Boito Júnior (2002, cap. I, item 4).
} 
muito limitadas da burguesia industrial ao neoliberalismo. Ignoram que a indústria é parte da classe capitalista e que, nessa medida, o modelo tem algo a oferecer-lhe. As grandes empresas que se acredita respeitarem a legislação trabalhista também usufruem, mesmo que indiretamente, por meio de seus fornecedores e da prática da subcontratação, a desregulamentação do mercado de trabalho e a redução dos custos que essa desregulamentação propicia; a "mercadorização" de direitos e de serviços como saúde, educação e previdência também atende, de modo variado, diferentes setores da burguesia. Em primeiro lugar, ela estimula a expansão dos negócios de uma nova fração burguesa que denomino "nova burguesia de serviços”, beneficiária direta do recuo do Estado na área dos serviços básicos. Como veremos adiante, o crescimento da nova burguesia de serviços é apenas uma das modificações promovidas pelo modelo neoliberal na composição da burguesia brasileira. Em segundo lugar, a "mercadorização" reduz os gastos sociais tradicionais do Estado, atendendo à pressão do grande capital para apropriar-se do orçamento público. A desregulamentação e a "mercadorização" foram mantidas pelo governo Lula. Ele preservou as reformas promovidas por FHC, além de ter realizado e estar preparando novas reformas - da previdência, do estatuto do servidor público (generalização da contratação no modelo da Consolidação das Leis do Trabalho (CLT)), trabalhista e sindical, privatização de hospitais e universidades e outras. Esse elemento do modelo neoliberal recupera - parcialmente e em uma situação histórica nova - aquela que era uma característica do modelo capitalista vigente no período anterior a 1930: o mercado de trabalho desregulamentado e a ausência de direitos sociais.

Se o desmonte dos direitos trabalhistas e sociais garante a unidade política da burguesia em torno do programa neoliberal, os demais elementos do neoliberalismo têm dividido a classe burguesa no plano corporativo dos interesses de fração. A maior parte dos trabalhos que utiliza o conceito de classe social para analisar a burguesia ignora essa divisão, imaginando uma classe burguesa com interesses homogêneos frente ao modelo neoliberal e favoráveis integralmente a ele, o que impede esses trabalhos de explicarem os conflitos que tal modelo tem ensejado entre os próprios empresários. Trata-se de uma abordagem que comete, digamos assim, o erro simétrico e oposto àquele anteriormente citado e que consistia, como dissemos, em separar a indústria do conjunto da classe capitalista. Pois bem: é examinando essa divisão que podemos verificar quais interesses burgueses são priorizados e quais são negligenciados ou preteridos pela política neoliberal.

O segundo elemento do modelo a ser considerado é a política de privatização, que reduziu muito o capitalismo de Estado brasileiro que fora um dos elementos propulsores da industrialização capitalista no período posterior a 1930. Novamente, o rompimento com o modelo capitalista desenvolvimentista é evidente, embora as conseqüências políticas desse fato não sejam evidentes para muitos estudos sobre o assunto. A privatização, nessa nova fase do capitalismo brasileiro, atende diretamente aos interesses dos grandes grupos econômicos privados, ou seja, do conjunto do grande capital - nacional ou estrangeiro, industrial ou financeiro. Já a média burguesia permaneceu, devido às regras estabelecidas pelo Estado brasileiro para o processo de privatização, excluída do grande negócio que foram os leilões de empresas estatais. Menos de 100 grandes grupos econômicos privados apoderaram-se da quase totalidade das empresas estatais que foram a leilão, contando com favorecimentos de todo tipo - subestimação do valor das empresas, possibilidade de utilização das chamadas "moedas podres", financiamento subsidiado pelo Banco Nacional de Desenvolvimento Econômico e Social (Bndes), informações privilegiadas, preferência e ajuda das autoridades governamentais etc. Grandes empresas industriais, como os grupos Votorantin, Gerdau e Vicunha; grandes bancos, como Itaú, Bradesco, Unibanco e o Bozzano-Simonsen; grandes empresas estrangeiras, como as empresas portuguesa e espanhola na área de telefonia, enfim, o grande capital nacional, industrial ou financeiro, e o grande capital estrangeiro, isto é, a cúspide do capitalismo brasileiro apropriou-se da siderurgia, da petroquímica, da indústria de fertilizantes, das empresas de telecomunicação, da administração de rodovias, dos bancos públicos, das ferrovias etc. O resultado foi que a participação das estatais no produto interno bruto (PIB) brasileiro caiu muito ao longo das duas últimas décadas ${ }^{5}$. As

5 Entre 1989 e 1999, dentre as 40 maiores empresas operando no Brasil, o número de empresas estatais caiu de 14 para apenas sete empresas (DINIZ \& BOSCHI, 2004, p. 69). 
empresas privatizadas estão hoje entre as mais lucrativas do capitalismo brasileiro. O governo Lula herdou e manteve essa privatização, inclusive os contratos leoninos que asseguram alta lucratividade aos novos monopólios privados, e nem sequer cogitou de investigar os casos de corrupção mais rumorosos que envolveram a política de privatização. Além disso, as empresas privatizadas que se dizem em dificuldades, como a Ferronorte, vêm recebendo ajuda financeira privilegiada do atual governo, o que contraria os objetivos declarados da política de privatização. A legislação criada pelo governo Lula para as parcerias público-privadas (PPPs) para serviços públicos e de infra-estrutura é a sua mais ambiciosa proposta na área da privatização. Serão esses mesmos grandes grupos econômicos que monopolizarão o acesso à exploração dos serviços de infra-estrutura com o privilégio de terem, conforme estabelece a legislação das PPPs, a lucratividade assegurada em lei - está prevista a suplementação de dinheiro público para os empreendimentos que não atingirem a "lucratividade esperada".

A política de privatização é um elemento do modelo neoliberal que atinge de modo desigual os diferentes setores da burguesia. Ela tem, como indicamos, aumentado o patrimônio e os lucros do grande capital em detrimento do médio capital e ferido os interesses da camada burocrática que controlava essas grandes empresas estatais. A redução das empresas estatais significa, do ponto de vista da estrutura de classes, a redução de um setor da burguesia nacional, pois a cúpula dessas empresas funcionava como uma burguesia nacional de Estado. Juntamente com a expansão da nova burguesia de serviços, essa é outra mudança importante que ocorreu na composição da burguesia brasileira. Tal fato tem uma conseqüência política que vem sendo, como anunciei, ignorada nos estudos sobre a matéria: ela restringe a base social e a influência política do nacionalreformismo burguês no Brasil 6 .

Finalmente, no que diz respeito ao terceiro elemento da política neoliberal que julgamos importante, que são a abertura comercial e a

\footnotetext{
${ }^{6}$ Desenvolvi esse ponto no meu já citado trabalho Política neoliberal e sindicalismo no Brasil (cf., especialmente, BOITO JÚNIOR, 2002, parte I, cap. 3-4).
}

desregulamentação financeira, nesse caso, até um setor importante do grande capital privado, o industrial, teve seus interesses negligenciados ou preteridos em proveito do grande capital financeiro nacional e internacional.

Para a análise do capital financeiro e do atual modelo de acumulação, seguimos François Chesnais, para quem a forma dominante de capital hoje é o financeiro, concebido como "[...] a fração do capital que se valoriza conservando a forma dinheiro" (CHESNAIS, 1997, p. 31). O grande capital financeiro no Brasil é diversificado quanto à origem do capital, ao tipo de inserção no mercado brasileiro e à área de atuação. Temos, acima de tudo, os grandes bancos comerciais nacionais e estrangeiros - que possuem rede de agências no Brasil - Bradesco, Itaú, Unibanco, Santander, HSBC e outros. Dados do final da década de 1990 apontavam que, em um universo de 200 bancos funcionando então no Brasil, um total de 25 deles detinham, sozinhos, mais de $80 \%$ do ativo total. O balanço dos lucros dos bancos no primeiro trimestre de 2005 mostrava que os cinco maiores bancos do país respondiam por $69 \%$ de todo o lucro do sistema bancário; se considerados os dez maiores, essa parcela subia para 83\% do total dos lucros ${ }^{7}$. No Brasil, grandes bancos e grandes grupos industriais mantêm-se relativamente separados e uma particularidade brasileira no quadro da América Latina é a importância dos grandes bancos nacionais, setor que, aliás, até meados da década de 1990 não apresentava investidores estrangeiros dignos de nota (cf. MINELLA, 1997). As demais empresas e instituições que integram o capital financeiro são os bancos estrangeiros comerciais e de investimentos que, sem terem rede de agências no Brasil, possuem investimentos de curto e de longo prazo no país e os fundos e investimento e os fundos de pensão nacionais e estrangeiros. No Brasil e em outros países dependentes, esse capital financeiro funciona, em grande medida, como capital usurário e predador - o capital dinheiro portador de juro que se valoriza, a taxas muito elevadas, sem financiar a produção capitalista (posse dos títulos da dívida pública, fornecimento de empréstimo

\footnotetext{
7 O levantamento foi feito pelo Banco Central do Brasil em um universo considerado de 106 instituições bancárias (cf. LUCRO DOS BANCOS CRESCE, 2005, p. B-9).
} 
ao consumidor a taxas que chegam a $8 \%$ ao mês, empréstimo consignado, a taxas ditas "populares”, dirigidos a assalariados e aposentados de baixa renda etc.) ${ }^{8}$.

Para que o grande capital financeiro possa valorizar-se com rapidez e a taxas elevadas, alguns aspectos da política de Estado são, nas condições atuais e principalmente nos países dependentes, fundamentais: a) a integração do mercado financeiro nacional com os mercados internacionais, isto é, a desregulamentação financeira que assegura a livre conversão das moedas e a livre circulação das aplicações em títulos públicos e em bolsas de valores; b) o câmbio relativamente estável e livre que permita a conversão e a reconversão das moedas sem sobressaltos ou prejuízo; c) o pagamento da dívida pública externa e interna com taxa básica de juro real elevada para assegurar uma alta remuneração para os títulos públicos detidos, majoritariamente, pelas empresas que têm maior liquidez, isto é, pelo próprio capital financeiro. Os balanços dos grandes bancos privados brasileiros mostram que, ao longo dos últimos anos, a receita oriunda do recebimento de juros dos títulos da dívida pública representa cerca de $40 \%$ da receita total dessas instituições; d) liberdade para o capital financeiro cobrar o máximo possível pelo capital que cede emprestado a capitalistas e consumidores - spread liberado - e e) ajuste fiscal que garanta o pagamento dos juros dos títulos da dívida pública - nos paises europeus, déficit público limitado; nos latino-americanos, superávits primários. Sabemos que todos esses cinco elementos foram mantidos ou aprofundados durante 0 governo Lula.

A desregulamentação financeira está vinculada ao avanço recente da desnacionalização das economias dependentes como o Brasil e também à abertura comercial que foi promovida nesses países. De um lado, a compra e a venda de ações ou mesmo a aquisição de empresas públicas e privadas é um dos terrenos para a valorização do

\footnotetext{
$\overline{8 \text { Embora o capital dinheiro mantenha-se sempre exterior à }}$ produção, ele funciona como capital que poderíamos denominar de "indiretamente produtivo" quando é emprestado ao capitalista ativo que vai, este sim, convertê-lo em meios de produção e em força de trabalho para a geração de maisvalia, o que não ocorre com o capital usurário (cf. os textos recentes de CHESNAIS et alii, 2005).
}

capital financeiro internacional e, de outro lado, os grandes grupos industrial-financeiros dos países dominantes exigiram a abertura comercial da América Latina para aumentarem as suas exportações para essa região (CHESNAIS, 1997, p. 310). Como é sabido, a política neoliberal suprimiu o protecionismo dos mercados internos latino-americanos - protecionismo que fora a marca do modelo desenvolvimentista. Essa abertura, além de atender aos interesses do capital internacional, tem o objetivo de inibir, ao acuar a burguesia interna com a concorrência de produtos importados a preço menor, a remarcação de preços dos produtos industriais, contendo a inflação interna e contribuindo, assim, para a estabilidade interna da moeda e para a relativa estabilidade do câmbio. Essa política provocou, no primeiro governo FHC, sucessivos déficits na balança comercial, o que era "compensado" da maneira que melhor convinha aos interesses do capital financeiro: taxa básica de juros elevadíssima para atrair capital financeiro estrangeiro volátil em busca de valorização rápida e elevada, compensando com o ingresso desse capital de risco de curto prazo o desequilíbrio da balança comercial e das contas externas. Claro que tal política poderia produzir mais à frente como de fato produziu - uma dívida pública e um desequilíbrio externo cada vez maiores.

A abertura comercial e a desregulamentação financeira atendem, portanto, aos interesses do grande capital financeiro, nacional e internacional, em detrimento mesmo da grande indústria interna. Esta perdeu o mercado cativo para seus produtos, passou a pagar muito mais caro pelo capital que toma emprestado para investimentos e sofreu a redução da parte da receita do Estado destinada à infra-estrutura e ao fomento da produção. Alguns autores enfatizam que os grandes grupos industriais também separam parte do seu capital para investir no mercado financeiro. Nosso entendimento, contudo, é que esse fato não anula as perdas que a política monetária e de abertura comercial acarretam para a indústria ou, pelo menos, não faz que os grupos industriais deixem de pressionar contra essas perdas.

Concluindo, podemos afirmar que o grande capital financeiro nacional e internacional é a fração burguesa hegemônica no modelo neoliberal porque todos os aspectos da política neoliberal o desmonte do direito do trabalho e social, a privatização, a abertura comercial e a 
desregulamentação financeira - atendem integralmente aos interesses dessa fração da burguesia. Com exceção do primeiro aspecto, todos os outros contrariam, em maior ou menor medida, os interesses das demais frações integrantes do bloco no poder - médio capital, burguesia de Estado, grande capital industrial. O resultado prático da correspondência objetiva entre o modelo capitalista neoliberal e os interesses financeiros é a taxa de lucro superior que o sistema financeiro tem obtido ao longo dos últimos anos frente à taxa do setor produtivo. Entre 1994 e 2003, segundo levantamento da ABM Consulting, o lucro dos dez maiores bancos brasileiros cresceu nada menos que 1 039\% (LUCROS DOS BANCOS SOBEM, 2004, p. B-3). Durante o primeiro ano do governo Lula, os bancos voltaram a bater recordes de lucratividade. Alguns levantamentos feitos pela Economática e pelo Instituto Brasileiro de Planejamento Tributário (IBPT) mostraram que o investimento em fundos rendeu, no mesmo período, quatro vezes mais que o investimento nos setores produtivos; sobre esses investimentos incidem menos impostos (FUNDOS RENDEM 4 VEZES, 2004, p. B-1, B3, B4). No decorrer do primeiro trimestre de 2005, o lucro dos bancos manteve a trajetória de alta - cresceu 52\% em relação ao mesmo período de 2004 (LUCRO DOS BANCOS CRESCE, 2005, p. B-9).

Acrescentemos que, além da correspondência objetiva entre os interesses do grande capital financeiro e o modelo neoliberal, verifica-se, também, a identificação política e ideológica das entidades nacionais e internacionais do capital financeiro com os sucessivos governos neoliberais no Brasil. A política desses governos, de Fernando Henrique Cardoso a Luiz Inácio Lula da Silva, vem sendo aprovada pelo Fundo Monetário Internacional (FMI), pelo Banco Mundial e pela Federação Brasileira de Bancos (Febraban). Indicador significativo dessa situação é a simbiose que se verifica entre o pessoal dirigente dos sucessivos governos do período, principalmente os pessoais do Ministério da Fazenda e do Banco Central, e o pessoal dirigente do setor financeiro nacional e internacional. Iniciar a carreira como diretor do Banco Central e prossegui-la como executivo de banco privado ou fazer o caminho inverso é, há anos, um fato corriqueiro no cenário político brasileiro. Como veremos adiante, o governo Lula apresenta algumas mudanças secundárias nessa matéria.

\section{A ASCENSÃO POLÍTICA DA BURGUESIA INDUSTRIAL E DO AGRONEGÓCIO NO GOVERNOLULA}

A hegemonia política do grande capital financeiro nacional e internacional não se exerce sem resistência e nas mesmas condições ao longo de todo o período neoliberal. Alguns intelectuais críticos, talvez devido ao grande desajuste entre a imagem pública do Partido dos Trabalhadores (PT) e o curso real do governo Lula, foram levados a enfatizar, de modo unilateral e errôneo em nosso entendimento, o elemento de continuidade entre FHC e Lula ${ }^{9}$. Nossa análise é diferente. Como dissemos, a novidade do governo Lula é que ele promoveu uma operação política complexa que consistiu em possibilitar a ascensão política da grande burguesia interna industrial e do agronegócio, principalmente dos setores voltados para o comércio de exportação, embora, é verdade, não tenha quebrado a hegemonia das finanças e tampouco alterado a posição subordinada do médio capital no bloco no poder ${ }^{10}$.

Durante o seu primeiro mandato, Fernando Henrique Cardoso ampliou a abertura comercial, promovendo mais uma rodada de suspensão de barreiras alfandegárias e não-alfandegárias às importações; ampliou a desregulamentação do ingresso e saída de capitais; manteve o câmbio valorizado, aumentou a taxa de juros e a dívida pública. Acumulou déficits crescentes na balança comercial e fez um ajuste fiscal duro - embora esse ajuste possa parecer, nos dias de hoje, um ajuste brando, tendo em vista o nível elevadíssimo de superávit primário imposto pelo governo Lula ao país. Segundo os dados do Banco Central do Brasil, FHC obteve, em porcentagem do PIB nacional, $0,27 \%, 0,08 \%$ e $0,01 \%$ de superávit primário, respectivamente, em 1995, 1996 e 1998; no ano de 1997, ocorreu um pequeno déficit primário de $0,95 \%$ do PIB. Dois aspectos dessa política foram particularmente criticados pela grande burguesia industrial interna: a abertura comercial e o nível da taxa de juros. Durante o primeiro governo FHC, a Federação das Indústrias do Estado

\footnotetext{
9 Penso em trabalhos de críticos de esquerda ao governo Lula como Francisco de Oliveira e Leda Paulani (cf. PAULANI, 2007).

10 Retomo nesta parte idéia que desenvolvi no artigo "A burguesia no governo Lula” (BOITO JÚNIOR, 2005).
} 
de São Paulo (Fiesp), secundada pela Confederação Nacional da Indústria (CNI), vocalizou a insatisfação desse setor.

Neste ponto da nossa análise, é obrigatório considerar a presença política das classes trabalhadoras. Podemos distinguir, metodologicamente, os empresários do restante da sociedade para elegê-los como objeto de estudo. Porém, o que se passa no interior da classe capitalista relaciona-se com o restante do mundo político e social. Dependendo das características do setor empresarial considerado e da sua inserção no conjunto das relações políticas, ele pode lograr estabelecer alianças ou frentes com setores das classes populares, que estão excluídas do bloco no poder. No caso em exame, é importante lembrar que os grandes industriais contaram, nesse protesto contra as políticas de abertura e de juros, com o apoio da Central Única dos Trabalhadores (CUT) e da corrente majoritária do Partido dos Trabalhadores, principalmente de sua seção paulista. A CUT, dirigida por uma nova aristocracia do trabalho representada por trabalhadores qualificados da indústria automotiva, do setor petroleiro e dos bancos, aspirava, apesar dos protestos da minoria de esquerda da Central, à ressurreição do velho desenvolvimentismo, que, acreditavam os sindicalistas, seria obtido com a redução da taxa de juros e outras medidas de incentivo ao investimento. A proposta de câmaras setoriais apresentada pela CUT no início da década de 1990 era concebida como o espaço privilegiado dessa aliança, em que empresários e trabalhadores de cada setor discutiriam, juntamente com o governo, aqueles que seriam os pontos de estrangulamento da produção e do emprego - financiamento, impostos, política de contratação etc. Essas câmaras eram pensadas, basicamente, para o setor industrial e a única que vingou foi a Câmara do Setor Automotivo, posteriormente fechada pelo governo FHC. Além das câmaras setoriais, em inúmeras ocasiões a Fiesp e a CUT trabalharam conjuntamente na elaboração de propostas e de projetos de política econômica - como na proposta de reforma tributária, elaborada pela Fiesp e pela CUT com a participação da Fundação Instituto de Pesquisas Econômicas, vinculada à Universidade de São Paulo (FIPE-USP), proposta que visava a "desonerar o capital produtivo".

Houve um momento alto dessa aliança quando, em junho de 1996, a diretoria da Fiesp decla- rou publicamente, inclusive por meio de texto assinado pelo seu Presidente e publicado na grande imprensa, apoio a uma greve nacional de protesto contra o desemprego que estava sendo organizada pela CUT e pela Força Sindical. A Fiesp, durante os meses de maio e junho daquele ano, estava organizando em Brasília, com a colaboração da CNI, uma manifestação de industriais de todo o país contra "o ritmo acelerado" da abertura comercial, contra o "ritmo lento" das privatizações e contra a política de juros. O governo FHC sentiu a pressão e, sem alterar a sua política geral, efetuou um recuo: apoiou-se nas normas da Organização Mundial do Comércio (OMC) - salvaguarda, direitos compensatórios e proibição ao dumping - para criar barreiras à importação de tecidos da China, da Coréia do Sul e de Formosa e à importação de brinquedos ${ }^{11}$. Na campanha eleitoral de 2002, o PT e seu candidato, Luiz Inácio Lula da Silva, esforçaram-se para atrair o apoio da Fiesp, proferindo um discurso segundo o qual fariam o governo da produção contra a especulação. Pareciam reeditar as tradicionais ilusões da esquerda brasileira no suposto papel político da "burguesia nacional".

Além dessa pressão política, é preciso considerar um fator econômico. Os déficits crescentes na balança comercial do país, se atendiam aos interesses do capital internacional, poderiam, a médio e longo prazos, gerar problemas para o próprio capital financeiro nacional e internacional. $\mathrm{O}$ desequilíbrio das contas externas, provocado pelo pagamento da dívida, pela crescente remessa de lucros oriunda do avanço da internacionalização da economia e pela própria abertura comercial, poderia comprometer a capacidade de pagamento do Estado brasileiro e, no limite, se se chegasse a um nível muito baixo de reservas internacionais, poderia, inclusivamente, inviabilizar, por escassez de reservas, a liberdade básica do capital financeiro internacional de entrar e sair do país. A economia brasileira aproximou-se dessa situação crítica com a crise cambial de 1999, no momento de transição do primeiro para o segundo mandato de FHC. O fantasma daquilo que os

11 Os números da revista da Fiesp publicados entre abril e julho de 1996 dão ampla cobertura a esses acontecimentos e realçam a ação e os objetivos dos industriais - no mês de junho, a publicação da Fiesp trocou o título sóbrio Notícias pelo afirmativo Revista da Indústria 
desenvolvimentistas da Cepal denominavam de "estrangulamento externo" rondava as contas brasileiras com o exterior. A situação exigia alguma correção de rumo. Fernando Henrique Cardoso percebeu isso: demitiu da Presidência do Banco Central Gustavo Franco, o ideólogo da valorização cambial; desvalorizou o real; abandonou a política de déficit na balança comercial e adotou uma política de balança comercial superavitária. O saldo positivo na balança comercial e um acordo de emergência obtido com o FMI passaram a ser os trunfos de que dispunha o segundo governo FHC (1999-2002) para restaurar a confiança do capital financeiro internacional na economia brasileira. Esse foi o embrião da política de exportação que seria implementada em seguida pelo governo Lula ${ }^{12}$.

Diversos são, portanto, os fatores responsáveis pela nova política de comércio internacional e pela correspondente ascensão política da grande burguesia interna industrial e do agronegócio. Dado o economicismo que domina as análises da política econômica brasileira, é importante destacar os fatores políticos que induziram essa mudança - a pressão da grande burguesia industrial ao longo da década de 1990, a pressão convergente dos sindicatos e a própria vitória da candidatura Lula na eleição presidencial de 2002. Contaram também fatores econômicos nacionais e internacionais - a ameaça de estrangulamento externo que se evidenciou na crise cambial de 1999, o crescimento do comércio internacional de matérias-primas e de recursos naturais, a melhora nas cotações desses produtos, o declínio, na década de 2000, do fluxo de dólares dirigido aos países dependentes pelos fundos de aplicação dos países dominantes e, finalmente, a grande desvalorização cambial provocada, involuntariamente, pelo temor do capital internacional diante da iminente vitória de Lula em 200213. Uma vez no governo, Lula decidiu radicalizar na direção da correção iniciada no segundo governo FHC. Iniciou

12 Os setores industriais voltados para exportação aumentaram sua influência no interior da Fiesp ao longo da década de 1990, o que torna compreensível a posição atual da entidade face ao governo. Sobre esse ponto, ver Bianchi (2004).

13 O prosseguimento de nossa pesquisa deverá levantar um perfil mais preciso da grande burguesia interna, principalmente do seu ramo exportador. O lucro dos diferentes segmentos da grande burguesia interna são afetados de ma- a sua política agressiva de exportação, centrada no agronegócio, nos recursos naturais e nos produtos industriais de baixa densidade tecnológica e implementou as medidas cambiais, creditícias e outras necessárias para manter essa política. O próprio perfil da indústria brasileira mudou, com declínio dos setores mais sofisticados e ascensão dos setores industriais que processam recursos naturais - minérios, papel e celulose, produtos alimentícios etc. ${ }^{14}$. O carro-chefe das exportações é o agronegócio, setor responsável por cerca de $40 \%$ de todas as vendas do país no exterior - destacam-se o complexo da soja que lidera as exportações, seguido por carnes, madeiras, açúcar e álcool, papel e celulose, couros, café, algodão e fibras, fumo e suco de frutas (EXPORTAÇÃO DO AGRONEGÓCIO, 2005, p. B-3).

Tratou-se de uma vitória, ainda que parcial, da grande burguesia interna industrial e do agronegócio. Essa fração burguesa permaneceu como força secundária no bloco no poder, uma vez que o Estado continuou priorizando os interesses do capital financeiro, mas o governo Lula ofereceu a ela uma posição bem mais confortável na economia nacional. O resultado disso pode ser visto no comportamento da Fiesp. Essa entidade, que foi crítica dos aspectos mais financistas da

neiras distintas pela taxa de câmbio de acordo com pelo menos duas variáveis: se a fixação do preço da mercadoria da empresa ou do segmento é feita em moeda forte (como produtos agrícolas) ou em moeda nacional (como produtos industriais) e se a empresa ou segmento tem alto ou baixo índice de abertura. As empresas e segmentos que apresentam um baixo índice de abertura (importam pouca matériaprima, insumos e equipamentos) e têm o preço de suas mercadorias fixado em reais são as mais prejudicadas com a valorização cambial; no outro extremo, as empresas ou segmentos que têm os preços de suas mercadorias fixadas em moedas fortes e que apresentam um alto índice de abertura são os menos prejudicados pela valorização cambial. Boa parte do agronegócio ocupa uma posição intermediária entre essas duas posições extremas. Há alguns dados sistematizados sobre esse assunto por Fernando Pimentel Puga no texto "Câmbio afeta exportadores de forma diferenciada” (TORRES FILHO, PUGA \& FERREIRA, 2006. p. 65-70).

14 Fazendo o balanço do período 1992-2000, Ricardo Carneiro afirma: "O que se pode concluir do conjunto dos dados é que a estrutura do comércio exterior brasileiro refletiu fielmente as mudanças ocorridas na estrutura produtiva, com exportações concentradas em setores de menor conteúdo tecnológico, ocorrendo o inverso com as importações” (CARNEIRO, 2002, p. 334). 
política econômica e da abertura comercial dos anos 1990, é presidida hoje por um homem de confiança do Palácio do Planalto, que se elegeu para a Fiesp com o apoio do governo federal. O governo Lula multiplicou os canais institucionais de consulta aos industriais e aos exportadores, o que representa um grande contraste, segundo depoimentos dos próprios empresários, com o que se passava no governo FHC (cf. DINIZ, 2006).

Quanto ao tamanho das empresas exportadoras, predomina amplamente o grande capital. Segundo os dados da Associação Brasileira de Comércio Exterior, o Brasil tinha, em fevereiro de 2005, dezenove mil empresas exportadoras. Desse total, apenas 800 empresas eram responsáveis por $85 \%$ do total das exportações do país. Quanto à origem do capital, das 40 maiores empresas exportadoras brasileiras, responsáveis por $41 \%$ do total das exportações, são empresas estrangeiras 22 delas (MÚLTIS USAM PAÍS, 2004, p. B-1). O governo diz estimular a participação das pequenas e médias empresas nacionais nesse novo negócio da China mas, segundo os dados do Serviço Brasileiro de Apoio às Micro e Pequenas Empresas (Sebrae), no ramo industrial, as milhares de "micro" e pequenas empresas exportadoras respondem por apenas $2 \%$ das exportações do setor (REAL VALORIZADO, 2005, p. B-1). A política de "caça aos dólares” representa, portanto, uma política que atende aos interesses do grande capital nacional e estrangeiro vinculado à agroindústria, à extração mineral e aos produtos industriais de baixa densidade tecnológica. Novamente, o médio capital ocupa uma posição subordinada.

\section{ASCENSÃO POLÍTICA SEM CONQUISTA DA HEGEMONIA}

Por que então, apesar do estímulo governamental ao setor exportador e da alta lucratividade que esse setor está apresentando, entendemos que o grande capital financeiro nacional e internacional permanece hegemônico no interior do bloco no poder no governo Lula? A resposta é a seguinte: porque esse governo estimula a produção, mas no interior dos limites permitidos pelos interesses fundamentais do grande capital financeiro.

Em primeiro lugar, ele estimula, prioritariamente, a produção voltada para a exportação. Do ponto de vista das finanças, não interessa priorizar a produção voltada para o mercado interno. $\mathrm{O}$ grande capital financeiro necessita reduzir o desequilíbrio das contas externas, sem o que a sua livre circulação e sua elevada remuneração poderão ficar comprometidas. O objetivo principal do estímulo à produção deve ser, então, a exportação, isto é, a caça aos dólares e às demais moedas fortes - não é no consumo popular interno que essas moedas poderão ser obtidas. Por isso, estimula-se especificamente a produção para exportação e não a produção em geral. Em segundo lugar, mesmo na política de estímulo à exportação, tudo deve ser feito de modo a não ultrapassar a medida daquilo que interessa às finanças. Corrida aos dólares, sim; mas desde que os dólares obtidos sejam direcionados para o pagamento dos juros da dívida. Assim sendo, o superávit primário e os juros devem permanecer elevados mesmo que isso limite o próprio crescimento das exportações. De fato, faltam infra-estrutura e recursos humanos - estradas, silos, portos, funcionários para a vigilância sanitária etc. - para que o capitalismo brasileiro possa crescer pelo menos dentro da taxa média das principais economias latino-americanas e ainda que como mera plataforma de exportação. Porém, do ponto de vista do capital financeiro, não interessa desviar para a infra-estrutura o dinheiro que deve ser encaminhado para remunerar os bancos. Os pontos de estrangulamento poderão, quem sabe, ser superados pelas PPPs, concebidas pelo governo Lula justamente para contornar os problemas de infraestrutura sem ameaçar a política de elevados superávits primários. O mesmo raciocínio aplicase à política de juros básicos elevados, que fortalece o perfil usurário do capital financeiro, desvia-o do financiamento da produção e encarece os investimentos, limitando o crescimento da exportação. Pelo que podemos ver então, o superávit primário elevado e a alta taxa de juros não são, no governo Lula, um desvio financista incrustado em uma política globalmente desenvolvimentista. São, na verdade, consistentes com esse novo e modesto crescimento econômico voltado para a exportação. O aumento das exportações foi acompanhado do aumento do superávit primário, que saltou de uma média de $1 \%$ do PIB no primeiro mandato de FHC para 3,5\% no segundo mandato e, agora no governo Lula, está na casa de 4,5\%.

A política externa do governo Lula também expressa a nova situação do bloco no poder. $\mathrm{Ou}$ seja, ela não está desconectada da política interna, como sugerem aqueles que a consideram a "parte sã” desse governo. O Presidente Lula diz 
estar lutando por uma nova "geografia comercial" e é aqui que reside o segredo da vinculação da sua política externa com a sua política econômica. A política externa é, ao mesmo tempo, dependente (frente ao imperialismo) e conquistadora (frente às pequenas e médias economias da periferia). De um lado, reafirma-se a posição subalterna do capitalismo brasileiro na divisão internacional do trabalho com a política de especialização regressiva no comércio exterior mas, de outro lado, o governo quer ocupar de fato o lugar que cabe ao capitalismo brasileiro nos mercados agrícola, de recursos naturais e produtos industriais de baixa tecnologia, mesmo que para tanto o capitalismo brasileiro deva expandir-se às custas das demais burguesias latino-americanas e mesmo que gere tensões comerciais localizadas com alguns países dominantes. A luta contra o protecionismo agrícola da Europa e dos Estados Unidos e a deterioração das relações com a Argentina ilustram o que estamos afirmando.

O empenho do Estado brasileiro em construir uma aliança de estados da periferia, consagrada no denominado G-20, na reunião de Cancún da OMC em outubro de 2003, visa exatamente a suspender o protecionismo agrícola dos países dominantes. O discurso que o governo Lula aciona para legitimar a reivindicação do G-20 é um discurso neoliberal que pleiteia a "verdadeira abertura” dos mercados e concentra a luta no comércio de produtos agrícolas. Não estão excluídas, como se tem verificado, novas concessões na política de abertura comercial para produtos industriais e serviços em troca de recuo dos países dominantes no protecionismo agrícola. Ao proceder assim, o governo abdica de lutar por normas que regulem o comércio internacional visando a favorecer os países dependentes. Já a face hegemonista dessa política está abalando o Mercado Comum do Sul (Mercosul). A grande burguesia interna brasileira, como aliada subalterna do grande capital financeiro, aspira a ter acesso a porções crescentes do mercado latino-americano e essa aspiração está abalando a aliança com o capitalismo argentino no Mercosul.

\section{O REGIME POLÍTICO E A HEGEMONIADO CAPITAL FINANCEIRO}

Digamos, agora, uma palavra sobre o regime político que corresponde a esse bloco no poder. Como já indicamos, da nossa perspectiva teórica, a preponderância de um ramo do Estado sobre outro, o conflito entre os poderes Executivo e Legislativo, o sistema partidário e os conflitos variados no próprio interior do Estado e do governo devem, ponderados demais fatores intervenientes, ser remetidos aos conflitos entre as frações burguesas que compõem o bloco no poder. O hiperpresidencialismo brasileiro, que consiste, fundamentalmente, no apoderamento da função legislativa pelo poder Executivo federal, serve aos interesses da fração hegemônica no interior do bloco no poder. Tudo que se relaciona a esse arranjo político e institucional remete, obrigatoriamente, à disputa de interesses entre as frações burguesas. Um eventual fortalecimento do Congresso Nacional e dos executivos estaduais e municipais poderia representar uma ameaça à hegemonia do capital financeiro. O hiperpresidencialismo acarreta ainda, dada sua condição de regime político centrado na capacidade decisória da burocracia e na legitimidade de tipo burocrático em detrimento da legitimidade de tipo representativo, o declínio das funções governativa e representativa dos partidos políticos.

Não estamos afirmando que a cúpula da burocracia do Estado e a cúpula dos governos ajam em uníssono na defesa dos interesses do grande capital financeiro. São o Ministério da Fazenda e o Banco Central que se constituem nos locais privilegiados nesse esquema de concentração do poder em benefício da fração hegemônica. Eles são, por isso, os principais centros de poder na definição da política econômica - o Ministério da Fazenda é responsável pelo controle das variáveis macro-econômicas e determina a dotação orçamentária de todos os outros ministérios. Porém, em outros setores da cúpula burocrática e em outros centros de decisão do governo, tanto no período FHC quanto, mais ainda, no período Lula, o grande capital industrial e o agronegócio também detêm posições importantes a partir das quais procuram resistir às medidas de política econômica adversas a seus interesses. Durante os dois mandatos de Lula, esses atritos têm-se renovado: o antigo conflito entre José Dirceu (Casa Civil) e Antonio Palocci (Fazenda), entre Carlos Lessa (Bndes) e Henrique Meirelles (Banco Central), entre Dilma Roussef (Casa Civil) e, novamente, Henrique Meirelles etc. No período FHC, a proeminência de quadros políticos neoliberais extremados Pedro Malan, Gustavo Franco, Armínio Fraga sobre os neoliberais moderados - José Serra, 
Dorotéia Wernceck e outros - era mais clara. No governo Lula, a dinâmica desses conflitos no interior do governo é um dos indicadores do crescente fortalecimento da grande burguesia industrial interna e do agronegócio. No início do seu segundo mandato, em janeiro de 2007, Lula lançou o Plano de Aceleração do Crescimento, o PAC, que parece todo ele voltado para os interesses da grande burguesia interna, principalmente industrial. O Ministério da Fazenda passou a ser ocupado por um economista de formação heterodoxa, Guido Mantega, ficando o Ministério do Desenvolvimento nas mãos de um economista monetarista. Trata-se de uma inversão em relação ao conjunto do período FHC - quando o Ministério mais importante permaneceu sob controle de um economista ortodoxo, restando aos neodesenvolvimentistas o secundário Ministério do Desenvolvimento.

As frações subordinadas do bloco no poder, desigualmente contempladas pela política de Estado, têm maior acesso ao Congresso Nacional e aos ramos subordinados do Estado - governos estaduais e municipais - no regime político vigente. A experiência da história política recente mostra que, caso dependessem de decisão do Congresso Nacional, muitas das características do atual modelo econômico e muitas das decisões de política econômica encontrariam dificuldades, devido à publicidade que ganhariam e ao caráter heterogêneo da representação parlamentar - o grande capital financeiro não tem condições de homogeneizar o Congresso Nacional no mesmo nível que logra fazê-lo no núcleo do poder Executivo federal. Sempre que as reformas neoliberais exigiram reforma constitucional e, portanto, tiveram de passar pelo Congresso Nacional, as dificuldades foram grandes e muitas das reformas almejadas ou efetivamente tentadas não chegaram a sair do papel.

O sistema partidário é consistente com o papel preponderante do poder Executivo, a começar pelo Executivo federal. No neoliberalismo brasileiro, não existe governo de partido, mas partido do governo. Os deputados do partido de onde saiu o Presidente da República funcionam como mera base de apoio do governo no Congresso Nacional, tendo de enquadrar-se em decisões políticas para cuja elaboração não foram nem sequer consultados. Foi assim com o Partido da Social Democracia Brasileira (PSDB) nos dois governos FHC e está sendo assim, ao contrário do que muitos podiam esperar, com o PT durante os dois governos Lula. O resultado extremado do rebaixamento do poder Legislativo e da função governativa dos partidos políticos é que o regime político brasileiro produziu um conjunto de partidos, alguns de tamanho médio ou grande como o Partido Trabalhista Brasileiro (PTB), cuja única função é esta: servir de base parlamentar ao governo do momento em troca de favores. Os demais partidos dividem-se entre os interesses do grande capital financeiro e da burguesia interna. A ala majoritária do PSDB, vanguarda eleitoral do neoliberalismo no Brasil, representa o grande capital financeiro internacional e os interesses dos empresários e banqueiros brasileiros estreitamente ligados a esse capital. O PT, nascido como um partido socialdemocrata de esquerda e vinculado ao movimento sindical, desde meados da década de 1990, quando o então chamado Campo Majoritário iniciou o processo de reformulação programática e organizacional do Partido, vem realizando um movimento em direção à grande burguesia interna. Em sintonia com essa fração burguesa, o PT procura conter ou reverter apenas as medidas de política econômica que prejudicam essa fração da burguesia, como os juros elevados e a abertura comercial, mantendo aquelas que a favorecem mesmo que em detrimento do bem-estar dos trabalhadores - reforma da previdência, flexibilização do contrato de trabalho no setor público, reforma trabalhista etc. $\mathrm{O}$ antigo Partido da Frente Liberal (PFL), atuais Democratas, também representa os interesses financeiros internacionais, mas parece, dentre todos os grandes partidos, o mais vinculado aos interesses da nova burguesia de serviços. O Partido do Movimento Democrático Brasileiro (PMDB) possui basicamente três alas: uma governista, outra mais próxima dos interesses financeiros internacionais e uma terceira ainda ligada à média burguesia e à antiga burguesia de Estado. Mas, convém repetir, como o regime político reduziu muito a função governativa dos partidos, correspondentemente a sua função representativa também ficou minada. Os diferentes setores sociais percebem que o partido não é um instrumento importante de poder e dirigem suas luta e pressão diretamente para a burocracia de Estado. O resultado disso é que o vínculo representativo entre o partido e a sociedade fica debilitado.

Esse enfoque pode abrir perspectivas novas para a análise das lutas partidárias durante os dois governos Lula. Como pensar, nesse contexto, a 
ação do PSDB na sua postura de oposição ao governo, em episódios como a "Crise do mensalão" ou o movimento "Cansei”? Seria uma ação do partido do capital financeiro contra um governo que promove os interesses da grande burguesia interna industrial e do agronegócio? Inicialmente, durante a "Crise do mensalão", cheguei a pensar que não. Parecia-me que o PSDB estava deslocando-se de sua própria base ao voltar-se contra o governo, pois, naquela ocasião, as principais entidades do patronato fizeram questão de prestar apoio público ao governo Lula no pior momento da crise. A persistência dessa ação, contudo, parece indicar para um fenômeno orgânico. A disputa pela hegemonia no bloco no poder parece ter extravasado para o plano político-partidário (NUCCI JÚNIOR, 2007). O PSDB age como representante do capital financeiro e angaria apoio na alta classe média. Essa fração da classe média parece incomodada com a ampliação das políticas compensatórias durante o governo Lula, aquilo que poderíamos denominar o social-liberalismo desse governo. Devido à sua situação de classe, a alta classe média é atraída pelo discurso moralista contra a corrupção, isto é, o discurso que atribui a corrupção à índole malévola dos governantes e que acredita ser possível instaurar ou restaurar uma suposta natureza neutra e impessoal da qual teriam se desviado as instituições do Estado capitalista.

Voltemos à concentração do poder no Executivo federal. Há toda uma ideologia política que legitima essa concentração - ideologia sistematizada e difundida pelos representantes, conscientes ou inconscientes, do grande capital financeiro. São elementos dessa ideologia: a idéia segundo a qual a política monetária teria um caráter técnico; a defesa da medida provisória como conseqüência, também técnica, da necessidade de rapidez na ação de governar; a acusação unilateral do caráter fisiológico, paroquial e clientelista do Congresso Nacional, das emendas orçamentárias de deputados federais e senadores etc. Todas essas idéias legitimam a concentração do poder decisório no Executivo e a marginalização política do poder Legislativo. Algumas delas, como o caráter supostamente técnico da política monetária, idéia defendida, invariavelmente, desde o início dos anos 1990, por todos os presidentes e diretores que passaram pelo Banco Central, são pura mistificação; outras, como as acusações de fisiologismo, clientelismo e paroquialismo ao Congresso Naci- onal, aludem a dimensões verdadeiras da instituição, mas fazem-no de maneira a, também, produzir mistificações.

A detração do Congresso Nacional sugere uma suposta eficiência e grandeza política do poder Executivo; o discurso sobre o paroquialismo das emendas de deputados e senadores oculta que, na paróquia, estão as pequenas e médias empresas, justamente aquelas que a política econômica pretende marginalizar. A proposta de orçamento do poder Executivo federal que destina um terço das receitas da União para pagamento dos juros da dívida pública, isto é, para cerca de apenas $20 \mathrm{mil}$ famílias segundo os cálculos dos economistas, supõe-se técnica e racional, enquanto uma emenda de Deputado Federal ou Senador visando a asfaltar as ruas de uma pequena cidade ou financiar pequenas empresas é dita paroquial e fisiológica. Todo esse discurso esconde, ainda, que é a função que faz o político: é claro que um Congresso rebaixado atrai quadros políticos dispostos a servir, em troca de favores, como base passiva dos sucessivos governos - no limite, temos, cada vez em maior número, os fugitivos da Justiça que se candidatam para obter a imunidade parlamentar. Ou seja: o discurso em defesa do poder Executivo e do capital financeiro inverte os termos do problema: o efeito do rebaixamento político do Legislativo é apresentado como se fosse a sua causa. A porção de verdade que esse discurso ideológico contém é, portanto, apenas a quantidade necessária à sua eficácia como discurso mistificador.

\section{CONSIDERAÇÕES FINAIS}

Talvez seja possível detectar a lógica que está subjacente à hierarquia do bloco no poder no capitalismo neoliberal brasileiro. Essa lógica é sintetizada pela política econômica do Estado e resulta da inserção do capitalismo brasileiro nas mudanças ocorridas na divisão internacional do trabalho e da correlação política de forças no interior do país.

A política econômica define uma hierarquização das frações da classe capitalista privilegiando certas dimensões do capital em detrimento de outras: quanto à função do capital, privilegia a função financeira; quanto ao porte, privilegia o grande capital; quanto ao destino da produção, o mercado externo e a fatia de alta renda do mercado interno. A essas prioridades correspondem, uma a uma, as dimensões que são preteridas: quanto à função 
do capital, a produção, isto é, o capital ativo; quanto ao porte do capital, o pequeno e médio capital, e quanto ao destino da produção, o mercado interno de bens de consumo populares. Poderíamos estender a lista, lembrando que entre as grandes empresas estatais e a grande empresa privada, a política econômica privilegiou, principalmente na década de 1990 com os leilões de privatização, as grandes empresas privadas.

Tais prioridades consagram uma hierarquia do poder burguês que comporta duas posições extremas. No topo, temos o grande capital financeiro internacional e os grandes bancos nacionais, enquanto na base da pirâmide, temos o médio capital, aplicado no setor produtivo e voltado para o mercado interno de bens de consumo populares. O primeiro setor indicado concentra todas as vantagens cumulativas frente à política econômica e é um setor que age como fração distinta de classe; o segundo carrega todas as desvantagens cumulativas frente à política econômica e não chegou a constituir-se em fração autônoma da classe burguesa. Ainda falando das posições na hierarquia de poder, cabe indicar que a grande burguesia industrial e o agronegócio, principalmente as grandes empresas voltadas para a exportação, ocupariam uma posição intermediária entre aquelas duas posições extremas. Ficamos, então, com três posições: a fração hegemônica, cujos interesses têm sido priorizados pela política econômica tanto na década de 1990 quanto na década de 2000; a fração intermediária, que iniciou uma trajetória política ascendente sob o governo Lula e cuja conversão em fração hegemônica é uma possibilidade real - como já indicamos, a "globalização" não absorveu a totalidade da burguesia brasileira - e, por último, a fração marginalizada pela política de Estado, as pequenas e médias empresas do setor produtivo voltadas para o mercado interno de bens populares, cujos interesses sempre são ignorados quando colidem com os interesses do grande capital, seja ele financeiro ou produtivo, seja voltado para a exportação ou para o mercado interno. Esse é um quadro geral que considera as situações típicas. Há situações mais complexas, de setores que reúnem, ao mesmo tempo, dimen- sões privilegiadas e preteridas pela política econômica de Estado, como é o caso dos bancos de tamanho médio e das pequenas empresas voltadas para a exportação. Ao longo dos últimos anos, muitos bancos de tamanho pequeno ou médio foram levados à falência e muita pequena empresa voltada para exportação prosperou.

Este artigo restringiu-se ao tema do bloco no poder no período neoliberal, particularmente ao exame das relações da burguesia com o governo Lula. Não tratamos das relações dessa burguesia e do governo com as classes trabalhadoras, embora seja impossível separar completamente essas duas faces da política brasileira - como se viu, recorremos à presença política dos trabalhadores para poder analisar a ascensão política da grande burguesia interna. Há outras questões relacionadas à população trabalhadora e que poderiam ser motivo de exame. Por exemplo, o crescimento das políticas compensatórias, como o Programa Bolsa Família, pode repercutir significativamente na política econômica e nas posições relativas das frações burguesas no interior do bloco no poder? Poderia chegar a promover consideravelmente os negócios das médias empresas voltadas para o mercado de bens de consumo populares? As políticas de incentivo à produção industrial e ao agronegócio, voltados principalmente para a exportação, representam, em contraste com as políticas estritamente financistas, alguma melhoria para os assalariados e camponeses brasileiros? Nossa análise sugeriu que tais políticas são uma mudança muito limitada. Poderíamos acrescentar que descuram do desenvolvimento do mercado interno - pois em um modelo que privilegia a exportação o salário entra, primeiro, como custo e como desvantagem na competitividade internacional - e inviabilizam - devido ao papel estratégico atribuído ao agronegócio - a reforma agrária. Mas uma discussão como essa demandaria muito mais reflexão. Indicamos esses temas apenas para evidenciar que, ao tratar os empresários como classe dominante e não como um setor social qualquer, o nosso texto sugere, necessariamente, questões políticas e sociais mais amplas do Brasil contemporâneo.

Armando Boito Jr. (boito@uol.com.br) é Professor Titular do Departamento de Ciência Política da Universidade Estadual de Campinas (Unicamp), pesquisador do Centro de Estudos Marxistas (Cemarx) da mesma universidade e editor da revista Crítica Marxista. 


\section{REFERÊNCIAS BIBLIOGRÁFICAS}

BIANCHI, A. 2004. O ministério dos industriais - a Federação das Indústrias do Estado de São Paulo na crise das décadas de 1980 e 1990. Campinas. Tese (Doutorado em Ciências Sociais). Universidade Estadual de Campinas.

BOITO JÚNIOR, A. 2002. Política neoliberal e sindicalismo no Brasil. $2^{a}$ ed. São Paulo : Xamã.

2005. A burguesia no governo Lula. Crítica Marxista, Rio de Janeiro, n. 21, p. 52-77, primeiro semestre.

CARDOSO, F. H. 1966. Empresários de desenvolvimento. São Paulo : Difel.

CARNEIRO, R. 2002. Desenvolvimento em crise - a economia brasileira no último quarto do século XX. São Paulo : UNESP.

CHESNAIS, F. 1997. La mondialisation du capital. Paris : Syros.

CHESNAIS, F. ; DUMÉNIL, G.; LÉVY, D.; JOHSUA I. \& BRUNHOFF, S. (orgs.). 2005. Séminaire d'Études Marxistes : la finance capitaliste contemporaine et Marx. Paris : École des Hautes Études. Disponível em : http:// www.jourdan.ens.fr/levy/sem05.htm. Acesso em : 13.set.2007.

CODATO, A. N. 1997. Sistema estatal e política econômica no Brasil pós-64. São Paulo : Hucitec.

COSTA, P. R. N. 1998. Democracia nos anos 50 : burguesia, corporativismo e parlamento. São Paulo : Hucitec.

DINIZ, E. 2006. Empresários e governo Lula : percepções e ação política entre 2002 e 2006. Artigo apresentado no workshop Empresa, Empresários e Sociedade, realizado em Porto Alegre, de 2 a 5 de maio de 2006. Digit. Disponível em : http://www.fee.rs.gov.br/ 5workshop/pdf/mesa02_eli.pdf. Acesso em : 13.set.2007.
DINIZ, E. \& BOSCHI, R. 2004. Empresários, interesses e mercado. Belo Horizonte : UFMG.

IANNI, O. 1972. Estado e planejamento econômico no Brasil. Rio de Janeiro : Paz e Terra.

MEIRELLES, A. C. 1973. La révolution de 1930 : une révolution passive. Critique de l'économie politique, n. 16-17, 1973.

MINELLA, A. C. 1997. Elites financeiras, sistemas financeiros e governo FHC. In RAMPINELLI, W. J. \& OURIQUES, N. D. (orgs.). No fio da navalha. Crítica das reformas neoliberais de FHC. São Paulo : Xamã.

MONTEIRO, K. M. 2006. O desencantamento da razão : a ideologia política de Celso Furtado - 1972-1992. Campinas. Dissertação (Mestrado em Ciência Política). Universidade Estadual de Campinas.

NUCCI JÚNIOR, R. 2007. A oposição de direita ao governo Lula. Artigo escrito em 22 de ago. Disponível em : http:// onoctivago.blogspot.com/2007/08/possveisrazes-para-oposio-de-direita.html. Acesso em : 13.set.2007.

PAULANI, L. 2007. Brasil delivery : servidão financeira e estado de emergência econômico. São Paulo : Boitempo.

PERISSINOTTO, R. M. 1994. Classes dominantes e hegemonia na República Velha. Campinas : UNICAMP.

POULANTZAS, N. 1971. Pouvoir politique et classes sociales. Paris : F. Maspero.

1976. La crise des dictatures. Portugal, Grèce, Espagne. Paris : Seuil.

PUGA, F. P. 2006. Câmbio afeta exportadores de forma diferenciada. In : TORRES FILHO, E. T.; PUGA, F. P. \& FERREIRA, F. M. R. (orgs.). Visão do desenvolvimento. Rio de Janeiro : Banco Nacional de Desenvolvimento Econômico e Social.

\section{OUTRAS FONTES}

Exportação do agronegócio chega à marca dos US\$ 39 bi. 2005. Folha de S. Paulo, 7.jan., p. B-3.
Fundos rendem 4 vezes mais que produção. 2004. Folha de S. Paulo, 11.jun., p. B-1, B3-B4. 
Lucro dos bancos cresce 52\% no $1^{\circ}$ trimestre. Múltis usam país como base exportadora. 2004. 2005. Folha de S. Paulo, 4.jun., p. B-9. Folha de S. Paulo, 17.out., p. B-1.

Lucros dos bancos sobem mais de 1 000\%. 2004. Real valorizado já reduz base exportadora. 2005. Folha de S.Paulo, 21.jun., p. B-3.

Folha de S. Paulo, 27.maio, p. B-1. 
STATE AND BOURGEOISIE IN THE BRAZILIAN NEO-LIBERAL CAPITALIST MODEL Armando Boito Jr.

This article, fruit of ongoing research, engages in a type of analysis that has to a large extent been neglected in Brazil. Reaffirming ties to a rich tradition of Brazilian Sociology and Political Science a tradition that came into being in the 1960s and 1970s — the author attempts to examine the interests of fractions of the Brazilian bourgeoisie that come to act as distinct segments within the national political process and the relations that these interests maintain with the politics of the State. Conflicts between these fractions of the bourgeoisie and the relations that, as bourgeois fractions in a dependent country, the former develop with imperialism and with popular classes are also examined. In an approach that is always tentative and only a beginning, the article also makes reference to the shift in the bourgeois hierarchy of power, that is, the shift that occurred within the block in power during the two presidential mandates of Luis Ignácio Lula da Silva. We offer the hypothesis that dependent Brazilian capitalism's new position within internationalization did not impede the action and improved position of a powerful sector of the large bourgeoisie of this country within the block in power, a situation that developed over the first decade of the 2000s.

KEYWORDS: bourgeoisie; bourgeois fractions; neo-liberalism; Lula Government; entrepreneurial class; 


\section{ETAT ET BOURGEOISIE DANS LE MODÈLE NÉO-LIBÉRAL BRÉSILIEN}

\section{Armando Boito Jr.}

L'article, produit d'une recherche qui est en cours, cherche à effectuer une analyse qui a été assez délaissée au Brésil et reprend une tradition de la sociologie et de la science politique brésiliennes, tradition issue des années 1960 et 1970. L'auteur essaye d'examiner les intérêts des fractions de la bourgeoisie brésilienne qui agissent en fractions distinctes dans le processus politique national, ainsi que les relations de ces intérêts et la politique d’État. Sont également examinés les conflits entre ces fractions bourgeoises et les relations qu'elles entretiennent avec l'impérialisme et le champ des classes populaires puisqu'il s'agit des fractions bourgeoises d'un pays dépendant. Au moyen d'une approche initiale, l'article se reporte ausssi au changement dans la hiérarchie du pouvoir bourgeois, c'est-à-dire au changement survenu à l'intérieur du bloc au pouvoir, pendant les mandats du président Luis Ignácio Lula da Silva. Selon l'hypothèse formulée, une nouvelle vague d’internationalisation du capitalisme dépendant brésilien n’a pas empêché qu'un secteur très fort de la bourgeoisie interne agisse toujours et ait une position plus favorable au sein du bloc au pouvoir au long des années 2000.

MOTS-CLÉS: bourgeoisie; fractions bourgeoises; néo-libéralisme; Gourvernement Lula; entrepreneurs. 